\title{
$\mathrm{PH} 93$
}

\section{Información de bienes culturales. Campo de Níjar}

\author{
La Guía Digital del Patrimonio Cultural de Andalucía, desarrollada por el IAPH (http://www.iaph.es/web/ \\ canales/conoce-el-patrimonio/guia-digital/), nos ofrece, de forma integrada, toda la información patrimonial de \\ los municipios andaluces.
}

El Campo de Níjar es una comarca situada al sur de la provincia de Almería. Comprende una gran unidad geomorfológica interna que se extiende desde la vertiente meridional de Sierra Alhamilla hasta La Serrata. Los municipios que comprende esta demarcación son Níjar y Carboneras, al completo, y Almería, Lucainena de las Torres y Sorbas, de modo parcial.

Centro de Documentación y Estudios del IAPH

URL de la contribución <www.iaph.es/revistaph/index.php/revistaph/article/view/4128>

\section{Patrimonio inmueble}

En la Guía Digital del Patrimonio Cultural se encuentra la información referida a un total de 322 inmuebles, de los cuales el $53 \%$ corresponde al patrimonio etnológico, el $28 \%$ al arqueológico y el $19 \%$ al arquitectónico. La información sobre estos inmuebles se puede consultar también en la base de datos del Patrimonio Inmueble de Andalucía.

En la prehistoria, durante las edades del Cobre y el Bronce, los asentamientos se dispusieron alineados en las sierras norte y sur que delimitan el Campo de Níjar, ubicados en altura y controlando un área de captación de recursos minerales y agropecuarios. Los primeros asentamientos conocidos pertenecen a los momentos iniciales del Cobre Pleno, instalándose sobre terrenos propicios para el desarrollo de la agricultura. Como consecuencia de la llamada cultura de Los Millares se construyeron en esta época importantes conjuntos megalíticos, como El Barranquete (Níjar), con varias sepulturas de tipo tholos. En sierra Alhamilla se conservan otras necrópolis como El Tejar y Las Peñicas. Estos primeros asentamientos buscan tierras fértiles desarrollando importantes poblados como El Tarajal y Los Cerricos II, y otros más pequeños que se localizan en torno a estos. Con la llegada de los romanos ganan importancia las industrias y actividades relacionadas con los recursos de esta parte del litoral. En las primeras etapas de la dominación romana, los intereses principales eran el oro de Rodalquilar, las salinas y la pesca. De esta época es posible encontrar restos abundantes, como construcciones hidráulicas, restos de calzadas o enterramientos. En el periodo islámico se produce el proceso de integración territorial. Aparece entonces el núcleo de Níjar como emplazamiento defensivo y se conservan numerosas torres y recintos defensivos. Entre otros, el castillo de Huebro o el del Peñón de Inox. Entre las torres de vigilancia costera, podemos destacar las de Calahiguera, la torre de la Vela Blanca o la torre de la Testa.

Por otro lado, el clima subdesértico provocó la aparición de una cultura del agua especial y de profundo significado cultural. El patrimonio etnológico del sudeste peninsular está marcado por unas características que han dado forma y sentido a una manera de adaptarse al medio y al aprovechamiento del agua. En esta zona el patrimonio está determinado por las construcciones hidráulicas para captar, acumular y distribuir el agua, que han seguido utilizándose a los largo de los años, prácticamente inalterables desde su construcción: aljibes, norias, molinas, molinos de viento, molinos hidráulicos y pozos. Los sistemas de distribución del agua forman parte de un patrimonio diseminado y son elementos básicos de una forma de 
vida en en esta demarcación. Todos estos elementos se encuentran inscritos en el Catálogo General del Patrimonio Histórico Andaluz, con carácter genérico colectivo.

En relación con el patrimonio industrial, destacar las minas de oro de Rodalquilar; y en cuanto a la minería de hierro y plomo, sobresalen las instalaciones mineras de Lucainena de la Torres y el ferrocarril minero Lucainena-Agua Amarga, que cons- tituía un sistema de transporte que comunicaba las explotaciones mineras de hierro de Lucainena de la Torres en Sierra Almilla con el complejo de descarga para barcos situado en la costa de Agua Amarga. Son también muy interesantes las salinas Cabo de Gata, complejo industrial de elevado valor patrimonial producto en origen de un diseño empresarial para satisfacer las necesidades de la actividad salinera y sus trabajadores.

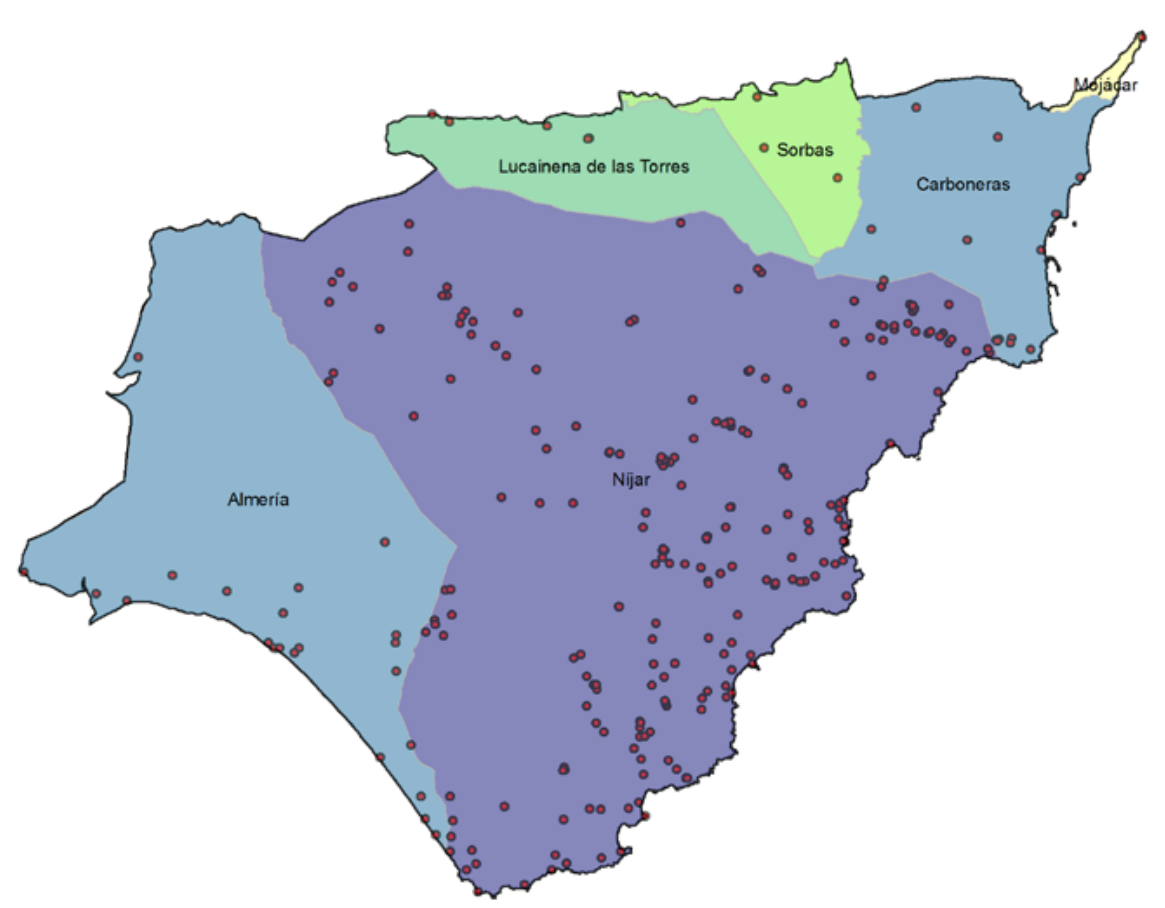

\section{LEYENDA}

- Inmuebles

\section{Densidad de Inmuebles por municipio}
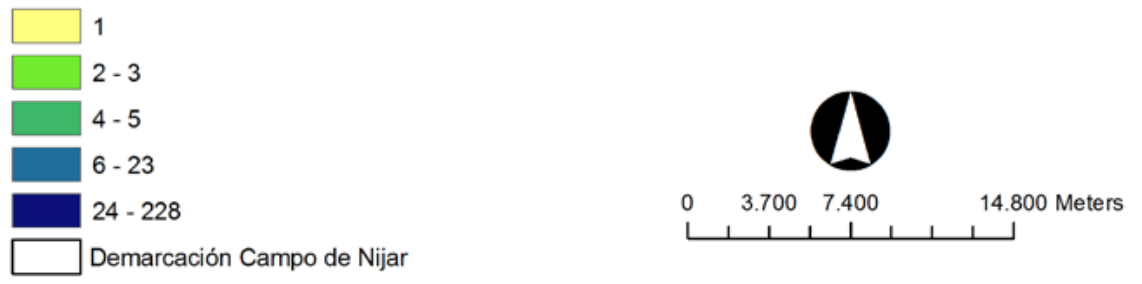

\section{Rutas culturales}

En la Guía digital encontramos: "De barro y agua, fuego y aire. Los históricos centros alfareros de la provincia de Almería" La cultura del barro en Almería tiene sus raíces en la historia, evidenciando la continuidad e importancia de esta actividad. En la provincia de Almería destacamos los centros alfareros de la zona de Albox, Sorbas, Níjar o Alhabia, que aún se mantienen en activo. Concretamente Níjar es uno de los centros alfareros más importantes y en su conjunto urbano se enclavan la mayoría de sus talleres. Emplazados aún en los mismos barrios y calles donde nacieron, estos alfares han sabido mantener en gran medida sus técnicas y sistemas de producción tradicionales que se caracterizan por una homogeneidad tan solo particularizada en las peculiaridades de cada taller. 